\title{
Cloud Storage : A Way to Modify Data Storage in Advance Aashutosh Umare ${ }^{1}$, Mohammed Bakhtawar Ahmed ${ }^{2}$ \\ 'Student, Amity University Chhattisgarh, Raipur, Chhattisgarh, India \\ ${ }^{2}$ Assistant Professor, Amity University Chhattisgarh, Raipur, Chhattisgarh, India
}

\begin{abstract}
Article Info

Volume 7, Issue 1

Page Number: 182-187

Publication Issue :

January-February-2021

\section{Article History}

Accepted : 01 Feb 2021

Published : 08 Feb 2021

Cloud computing is the rising innovation. Cloud computing gives simple access and superior figuring on the information. Another significant test that today's programming organizations face are capacity of information at reasonable cost and make accessible constantly. This paper gives the examination on prologue to distributed storage and virtual stockpiling design. Information stockpiling is a significant and important explore field in Cloud computing. We show how to improve the customary record stockpiling strategy dependent on eye OS Web working framework which figures it out document circulated capacity and deficiency tolerant control however HDFS innovation of Hadoop.
\end{abstract}

Keywords : Cloud Computing, Cloud Storage, Data Storage, Data Architecture

\section{INTRODUCTION}

Everyday, the use of information in the PC has been expanding from regular man to association. The enquiry emerges where to store the significant information, how to share the information, how to get to the information all inclusive, how to deal with the information, how to make information accessible constantly, in what capacity can all these be accomplished with sensible expense? The response to every one of these inquiries is cloud computing. Distributed computing as a model for engaging inescapable, supportive, on-demand arrange access to a typical pool of configurable figuring resources that can be immediately provisioned and released with inconsequential the board exertion or specialist organization communication.

\section{IMPORTANCE OF CLOUD COMPUTING}

1. Diminishes the support cost like no need of authorized programming expense for every framework, the acquisition of new equipment and programming is decreased.

2. Access to the application should be possible whenever, anyplace gave that they ought to be associated with web.

3. Adaptable

4. Improves Flexibility

5. Calamity Recovery

6. As the administrations depend on "Pay per use", capital use can be diminished

7. Easy to use Environment 


\section{CLOUD STORAGE}

Cloud storage is an assistance that looks after information, oversee and reinforcement remotely and made information accessible to clients over the system (by means of web).There are many distributed storage suppliers. The majority of the suppliers give free space up to specific gigabytes.For ex: Drop Box give free space up to 2GB, Google Drive, Box, Amazon, Apple Cloud give free space up to 5GB, Microsoft SkyDrive give free space up to 7GB [1].

Highlights like greatest record size, auto reinforcement, data transmission, overhaul for constrained space contrast starting with one supplier then onto the next supplier like most extreme document size in Drobox is $300 \mathrm{MB}$ whereas most extreme record size in Google Drive is 1TB.By utilizing distributed storage administration, clients need not contribute on capacity gadgets, even specialized help isn't required for upkeep, the capacity, reinforcement, fiasco recuperation [2].The idea of distributed storage in not worth when the customer can store and deal with the information requiring little to no effort when looked at using cloud. Along these lines, the cloud ought to be planned so that it is savvy, autonomic processable, multi-occupant, versatile, accessible, control, proficient.

\section{CLOUD STORAGE STANDARDS}

Capacity Network Industry Association TM distributed CDMI in the year 2009.This backingboth Legacy and New applications. Distributed storage measures characterize jobs and obligations regarding chronicling, recovering, information proprietorship. This likewise gives standard inspecting way with the goal that estimations are done in reliable way. These are useful to the distributed storage suppliers, distributed storage endorsers, distributed storage engineers, distributed storage administration intermediaries. By utilizing CDMI, distributed storage supporters can without much of a stretch distinguish the suppliers as indicated by their prerequisites.

\section{ISSUE PROCLAMATION}

From the prospective of data security, which has always been an important aspect of quality of service. Information put away on cloud servers isn't totally verify from infection. Whilewell-known cloud administrations, for example, google docs are equipped with infection examining programming. The information put away in the cloud might be as often as possible refreshed by the client including insertion, deletion, modification, appending, reordering and so forth. An unmistakable design for secure information stockpiling is outlined in underneath figure. Information stock piling in cloud is a process where theproprietor stores his information, documents and applications through a CLOUD STORAGE PROVIDER.

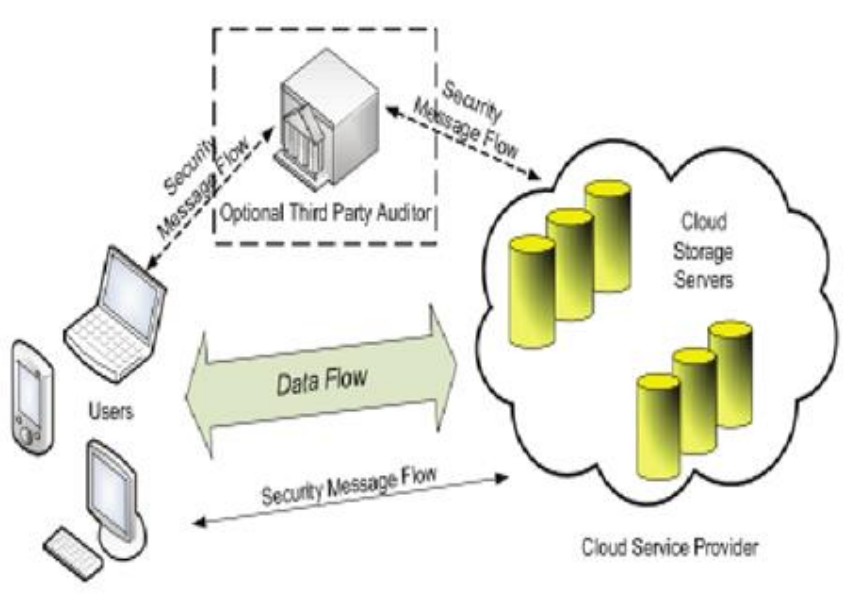

\section{SECURE CLOUD DATA ARCHITECTURE}

The flow examine furnishes cloud information security alongside limits the excess:

1) The dispersed convention in our work future gives the confinement of information mistake. Which just gives paired results about the capacity state over the circulated administration in forerunners. 
2) Tasks like Update, erase and uprightness are likewise giving in the proposition strategies.

3) Broad security and execution investigation show that the proposed plan is profoundly productive and flexible against Byzantine disappointment, pernicious information alteration assault, and even server Collusion assaults.

\section{VIRTUAL STORAGE ARCHITECTURE}

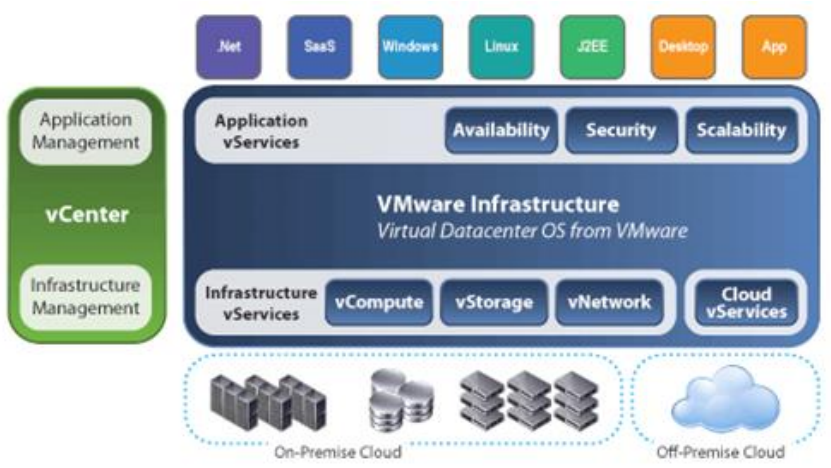

A significant piece of the cloud model is, the idea of a pool of assets that is drawn from upon the interest in little augments. The ongoing advancement that has made this conceivable is virtualization. Distributed storage is just the conveyance of virtualized stockpiling on request. This engineering depends on Storage Virtualization Model.

It comprises of three layers in particular

1. Interface Layer

2.Rule and Metadata Management

3. Virtual Storage Management.

In Interface Layer, Administrator and clients are furnished with the interface modes that may incorporate commands, customer internet browsers. The Rule and Metadata Management layer comprises of 2 sections Upper layer and Under layer. The upper layer comprises of discrete interface for customer and administrator. Physical gadget virtualization and information/record demand load adjusting is taken care by the Virtual Storage Management layer. Parameters like data transmission, turning speed and so on are kept up by URM. Framework keeps up a table holding these parameters and furthermore directing table. In the wake of breaking down all asset hubs, framework will gather the assortment in rationale space and structure a worldwide space finally. Also, Replica steering module is summoned when there is have to adjust the heap. Reproduction module is actualized by utilizing Fair-Share Replication calculation. In view of the entrance load factor, this calculation will recognize the best upand-comer hubs for reproductions substitution.

\section{COMPARISON CRITERIA}

Information and its administration are significant in cloud frameworks, and the essential driver behind moving to cloud is of the monetary nature, yet the procedure is increasingly unpredictable and must be assessed against a lot of criteria, out of which as most significant may be:

Security is one of the primary concerns when thinking about utilization of distributed storage administrations. The clients must be sure that their information is secure and dependable. The most significant security necessities and targets include:

$\checkmark$ Validation which is typically directed through enrollment and login process, so as to ensure against implication assaults and by implementing the utilization of solid passwords.

$\checkmark$ Approval which should empower secure document sharing and access control right approaches to shared records.

$\checkmark$ Classification of information, which is generally accomplished through the procedure of encryption. Furthermore, the reinforcement and synchronization incorporates arrange correspondence, and distributed storage suppliers should take measures to guarantee secure 
correspondence and document transmission between the customer and the server.

Accessibility, for example the distributed storage suppliers ought not experience the ill effects of single purpose of disappointment, have coordinated diagnostics and robotized fail over.

1. Availability is of equivalent worry as security viewpoints. The clients should be certain that their information isn't just undermined, yet is available at whatever point is required.

2. Service Level Agreement (SLA): distributed storage should explain exactly the levels of administration and assurances as far as information accessibility, information insurance and different QoS angles, and what clients are qualified for plan of action.

3. Programming interface: distributed storage frameworks normally give their own customer or program interface utilized for information move from nearby plate to distributed storage frameworks. Also, it is significant that distributed storage suppliers award their clients access to an application programming interface (API), which can be utilized to upgrade the abilities of third - party or in - house applications.

1. Free Storage: numerous merchants offer the likelihood with the expectation of complimentary distributed storage yet related with unassuming stockpiling limits. This foundation means the restriction of distributed storage limit offered by the seller at no monetary expense.

4. Most extreme Storage: while numerous merchants hypothetically offer boundless stockpiling limits, for some there is a furthest restriction of memory limit in cloud framework.

5. Most extreme File Size: many distributed storage suppliers limit the greatest record size that can be transferred to their servers for the most part because of execution debasement and to decline the heap of traffic to their servers. Archives, for example, monetary data, various reports and comparable possession records generally are the littlest sorts of documents and are anything but difficult to store on the web. In any case, as of late contemporary sight and sound gadgets can create media records of huge size, and the reinforcement of such documents can get prohibitive in some distributed storage servers.

6. Estimating plans: stockpiling suppliers charge their clients for the capacity or potentially for the transmission capacity utilization utilizing diverse evaluating plans. Capacity suppliers offer extraordinary estimating plans and we have dissected the most moderate evaluating plan.

7. Cell phone Support: in the hour of universal figuring gadgets, a run of the mill client in all likelihood will need to have the option to get to his information from different gadgets, which incorporates various PCs, yet contemporary cell phones, for example, advanced cells or tablet gadgets.

2. Stage Compatibility: this foundation alludes whether the distributed storage supplier underpins differing working frameworks, which thus suggests numerous equipment support also.

\section{THINGS NEEDED FOR EXECUTION}

1) Secure Software Development LifeCycle. The Security Development Lifecycle (SDL) is a programming improvement security confirmation process comprising of security rehearses assembled by seven stages Investigation, Analysis, Logical plan, Physical plan, Implementation, Maintenance. 
OBJECTIVE 1 : Investigation: Characterize venture forms and objectives, and record them in the program security approach.

OBJECTIVE 2 : Investigation: Analyse existing security arrangements furthermore, programs, dissect current dangers and controls, analyse legitimate issues, and perform hazard examination.

OBJECTIVE 3 : Intelligent configuration: Develop a security outline, plan episode reaction activities, plan business reactions to debacle, and decide the achievability of proceeding or potentially reappropriating the task.

OBJECTIVE 4 : Physical configuration: Select advancements to bolster the security diagram, build up a meaning of an effective arrangement, structure physical security measures to help innovative arrangements, and survey and endorse plans.

OBJECTIVE 5: Execution: Buy or create security arrangements. Toward the finish of this stage, present a tried bundle to the executives for endorsement.

OBJECTIVE 6 : Upkeep: Constantly screen, test, alter, update, and fix to react to evolving dangers.

\section{CLOUD STORAGE DATA MODULE}

Cloud information stockpiling, a client stores his information through a CSP into a lot of cloud servers, which are running in a synchronous, the client cooperates with the cloud servers by methods for CSP to find a good pace his data. In a few cases, the client may need to perform square level activities on his data. Users ought to be outfitted with security implies with the goal that they can make constant rightness affirmation of their put away information even without the presence of nearby duplicates. In a few cases, the client may need to perform square level activities on his data. Users ought to be outfitted with security implies with the goal that they can make constant rightness affirmation of their put away information even without the presence of nearby duplicates.

\section{CLOUD AUTHENTICATION SERVER}

The Authentication Server (AS) capacities as any AS would with a couple of extra practices added to the ordinary customer confirmation convention. The first expansion is the sending of the customer verification data to the disguising switch. The AS likewise works as a ticketing authority, controlling consents on the application organize.

\section{CONCLUSION}

This paper quickly clarified the issues of information security in cloud information stockpiling. And furthermore, gave a way out to guarantee client rightness. It also presents the key advancements and virtual stockpiling design in cloud. Distributed storage is more beneficial than customary capacity in view of its accessibility, adaptability, execution, movability and its utilitarian prerequisites. Actualizing virtualization in the distributed storage improves the versatility, accessibility and yet giving security in the virtual condition is mind boggling. So separated from virtualization, accentuation ought to be given in regards to security in virtual stockpiling. As per my review here we have work to implement more advancement on cloud storage with having a highly efficient security so that our data on cloud storage may remain safe.

\section{REFERENCES}

[1] http://www.baylor.edu/business/mis/nonprofits /doc.php/197132.pdf

[2] R.Aronika Paul Rajan , S.Shanmugapriya.(2012, May-Jun).Evolution of Cloud Storage as Cloud Computing Infrastructure Service.IOSRJCE.1(1), pp-38-45. 
[3] GurudattKulkarni,

RaniWaghmar,

RajnikantPalwe,

VidyaWaykule,

HemantBankar, KudilikKoli."Cloud Storage Architecture".IEEE International conference on Telecommunication Systems, Services, and Applications(TSSA)

[4] https://www.researchgate.net/figure/Clouddata-storage-architecture-15_fig1_271851848

[5] PravinO. Balbudhe, PradipO. Balbudhe. (2013, MAR).Cloud Storage Reference Model for Cloud Computing.IJIEASR.2(3), pp-81-85

[6] HaoLiu, ShijunLiu, XiangruMeng, Chengwei Yang, Yong Zhang(2010)."LBVS:A Load Balancing Strategy for Virtual Storage". IEEE International conference on Service Sciences.

[7] Quisar Rasool, Janzhong Li, George S.Oreku , Ehsan UllahMunir. (2008). Fair-Share Replication in Datagrid, Information Technology Journal.7(5), pp-776-782

[8] Mr. Mohammed Bakhtawar Ahmed, "Techniques for Fault Detection in Wireless Sensor Networks", International Journal of Engineering Science Invention (IJESI), PP. 65, 2018.

[9] Armbrust, $\mathrm{M}$ et al. Above the Clouds: A Berkley View of Cloud Computing. UC Berkley Technical Report, 2009.

[10] Cloud Storage Initiative. Implementing, Serving and Using Cloud Storage. https://www.snia.org/sites/default/files/201010WPImplementingServingandUsingTheCloud .pdf.

[11] Drago, I., Bocchi, E., Mellia, M., Slatman, H., Pras, A. Benchmarking Personal Cloud Storage. Proceedings of the 2013 conference on Internet measurement, pp. 205 - 212, 2013.

[12] Zhang, X., Guo, W., Qin, X. Performance Evaluation of Online Backup Cloud Storage. International Journal of Cloud Applications and Computing, vol. 3, no. 3, pp. 20- 33, 2013.

[13] Zheng, Q., Chen, H., Wang, Y., Zhang, J., Duan, J. COSBench: cloud object storage benchmark. Proceedings of the 4th ACM/SPEC International Conference on Performance Engineering, pp.199-210, 2013.

[14] Yash Jain, "Virtualization Concepts and Applications”, DA-IICT (DCOM Research Group).

[15] Siddharth Jain, Rakesh Kumar, Sourabh Kumawat, Sunil Kumar Jangir, (Novenber, 2014) "An analysis of security and privacy issues, Challenges with possible solution in cloud computing", National Conference on Computational and Mathematical Sciences (COMPUTATIA-IV), Technically Sponsored By : ISITA and RAOPS, Jaipur

\section{Cite this Article}

Aashutosh Umare, Mohammed Bakhtawar Ahmed, "Cloud Storage : A Way to Modify Data Storage in Advance", International Journal of Scientific Research in Computer Science, Engineering and Information Technology (IJSRCSEIT), ISSN : 24563307, Volume 7 Issue 1, pp. 182-187, JanuaryFebruary 2021. Available at doi : https://doi.org/10.32628/CSEIT217137 Journal URL : https://ijsrcseit.com/CSEIT217137 